\title{
A Six -Year Clinical, Microbiological and Radiological Study Outcome Following Treatment of Peri-implantitis
}

\author{
Abeer, S. Gawish* and Susan, A. Hassan** \\ Lecturer of Oral Medicine, Periodontology, Oral Diagnosis and Oral Radiology, ** \\ Associate Professor of Oral Maxillofacial Surgery, \\ Faculty of Dentistry, for Girls, Al Azhar University
}

\begin{abstract}
The present study evaluated the long-term outcome of a combined surgical and composite graft (bovine porous bone mineral BPBM and autogenous bone) in the treatment of peri-implantitis. Six individuals with titanium implants demonstrating a marginal bone loss. Baseline , 1 and 6 years measurements, including introral digital radiographs, gingival index (GI), probing depth(PD) and probing bone level (BL) were performed. In each implant subgingival bacterial samples were obtained and subjected to microbiological analysis by culture. Surgical exposure of the lesions and cleaning of the implants using hydrogen perioxide and2\% aqueous solution of chlorohexidine gluconate were performed. The autogenous bone was harvested from the chin combined with BPBM and packed into the bony defects. The treatment was evaluated clinically, microbiologically and radiographically at 1 and 6 years. Results: revealed a significant reduction in plaque and gingival bleeding. The mean probing depth was $6.94+1.16$ at the baseline and it was $1.91+1.21$ at the end of the study period. All treated implants showed bonegain. The mean gain in bone level was $5.12+0.5$ and radiological evaluation of bone density was measured at crest, mid-implant and lateral apical area of interest AOI $32.0+0.87,72.91+0.83,63.0+0.94$ at baseline and it reached $109.5+$ $0.53,141.63+1.19$ and $144.0+0.47$ respectively. The presence of putative periodontal pathogens significantly declined at the end of the study period.

\section{Conclusions:}

The results of the study suggest that the use of composite bone grafts as the treatment strategy for peri-implantitis lesions with maintenance of good oral hygiene appears to be an efficacious treatment approach for restoring hard tissue support of dental implants during the 6 year follow-up period.
\end{abstract}

\section{Introduction}

Implant dentistry is a relatively new and fast growing area of oral health services (18). Successful treatment results and patient satisfaction with dental implant treatment modalities must include prevention and treatment of peri-implant infections (25). Peri-implantitis and periodontitis are often described as inflammatory diseases with oral pathogens emerging either at implants, within the intraimplant components or teeth. Periimplantitis has been associated with gram- negative bacteria similar to periodontitis (5). Peri-implantitis has been associated with gram- negative bacteria similar to periodontitis (20). The goal of implant dentistry today should be the control of periodontal pathogens in the oral cavity. Once a peri-implant inflammatory process starts, implant sites get compromised by severe loss of peri-implant supported bone.

Meffert et al, (21) classified implants with complication into three types: Ailing implant in which bone loss accompanies 
pocket formation, but the implant is static at maintenance checks; failing implant with bone loss irrespective of therapy, and purulent exudate; and failed implant, showing mobility, dull sound on percussion and peri-implant radiolucency. Ailing and failing implants may be treated but failed implants must be removed because bone loss will continue. The failing implant is non-mobile with bone loss due to the following causes of peri-implantitis overheating of bone during placement, lack of sufficient bone.

To enhance the level of patient expectations and compliance, it is of special interest to determine whether it is possible to maintain the affected implant by bone grafting techniques or guided bone regeneration GBR procedures and rebuild the previously peri-implant tissues (18). Longitudinal studies have reported survival and success rates around $90-95 \%$ for osseointegrated titanium implants (10). Peri-implantitis has been reported to be prevalent in $4-15 \%$ of individuals with implants (30). Misch (23) suggested the use of bone grafts for management of failing implants. Various graft materials are being utilized today in an attempt to repair osseous defects around implants. Limited data are available regarding treatment of peri-implantitis in humans. The use of local or systemic antibiotics, mechanical debridement, guided tissue regeneration and autogenous bone grafts have been described in the literature $(24,27,30)$. In humans, only case reports are available (14) and longitudinal studies evaluating different treatment approaches in peri-implant diseases are lacking. Moreover, the studies performed so far are all short-term studies (less one year) and little is known about the implant survival rate on a long-term basis (6 years). The aim of this study was to evaluate the clinical, microbiological and radiological outcomes of the use of a composite graft as a treatment modality aimed at reconstructing intraosseous periimplant intrabony defects over a 6 year maintenance period in patients with loss of peri-implant supporting bone.

\section{Material and Methods \\ Subjects}

The data of this study were taken from six patients attending the outpatient clinic of Dental department $\mathrm{Al}$ Zahraa University Hospital, Faculty of Dentistry, Al Azhar University and the outpatient clinic of Oral Medicine \& Periodontology and Diagnosis Department, Faculty of Oral and Dental Medicine, Cairo University. The participants were four males and two females. Their ages ranged from 35-55 years, they suffered from peri-implant hard tissue break down around single tooth replaced implants*. The patients were systemically free from any systemic disease and evaluated by the aid of dental modification of Cornell Medical Index (17). Peri-implant parameters

Subjects fulfilling the inclusion criteria were invited to participate in the study and if accepted signed an informed consent form (baseline). All patients were monitored one year and 6 years after treatment. Gingival index, probing depths (the distance between the peri-implant gingival margin and the bottom of the periimplant pocket) and probing bone levels (under local anaesthesia; the distance from the implant shoulder to the deepest depth at which the probe meets strong resistance from contact with bone) were measured at 4 sites around the implant (midbuccal, distobuccal, midlingual, distolingual) Using a periodontal probe $0.4 \mathrm{~mm}$ diameter tip. The probing depths and probing bone level measurements (reproducibility $+1 \mathrm{~mm}$ in greater than 95\%) were performed by the same calibrated examiner.

Microbiological examination was performed at baseline (immediately when the patients attended to the study and before any hygienic treatment was carried out), then at one years and 6 years to detect any anaerobic microorganisms that may be located subgingivally. Each implant was isolated with cotton rolls after removing the supragingival plaque with a plastic curette. After air drying, a sterile paper point was inserted subgingivally and left for 30 seconds then dipped in $1 \mathrm{ml}$ of thioglycolate fluid medium using a calibrated loop. 


\section{Abeer, S. Gawish \& Susan, A. Hassan}

A sample of one micron was inoculated into a non-selective media of schaelder anaerobic agar plate enriched with sheep blood.

Selective media included a selective medium for non-sporing anaerobes NS and a selective medium for gram negative anaerobes (GN). All plates were incubated at $37 \mathrm{C}$ up to 15 days to allow the growth of slowly growing anaerobes. The plates were inspected every 48 hours to detect a newly growing colony type. Each colony that appeared was subjected to the following: Gram stained smear, subculturing on anaerobic plates that were incubated anaerobically to get a pure growth of strict anaerobic organisms.

The identification of anaerobes was made using the analytical profile index.

Microbiological examination comprised the incidence: which is the number of sites colonized by each member of the bacterial group.

\section{Radiographic assessment}

Radiographic follow-up was performed at baseline, 1 and 6years (fig. $1,2 \& 3)$ in order to evaluate the amount of bone formation. It depended on evidences of calcification and bridging on the periimplant bone defect by newly formed bone. Radiovisiography RVG was used in this study using the paralleling technique, which required a film holder that kept the sensor in a proper position in the mouth. The density value within marked points were measured at the crestal area of interest AOI, mid and lateral apical area of interest AOI .

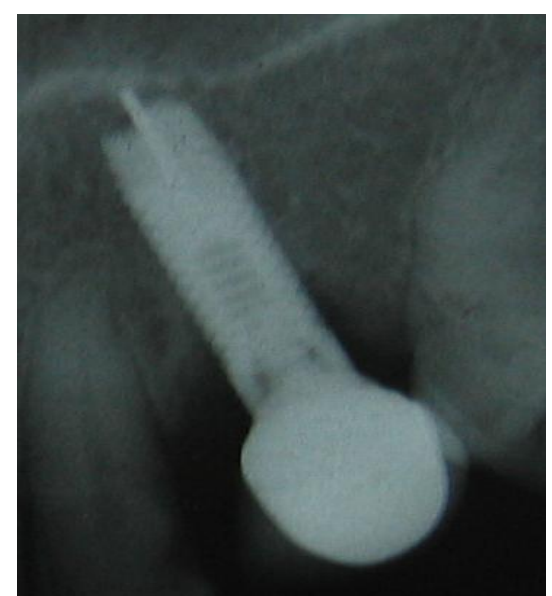

Fig 1: baseline radiograph showing osseous defect along the implant 


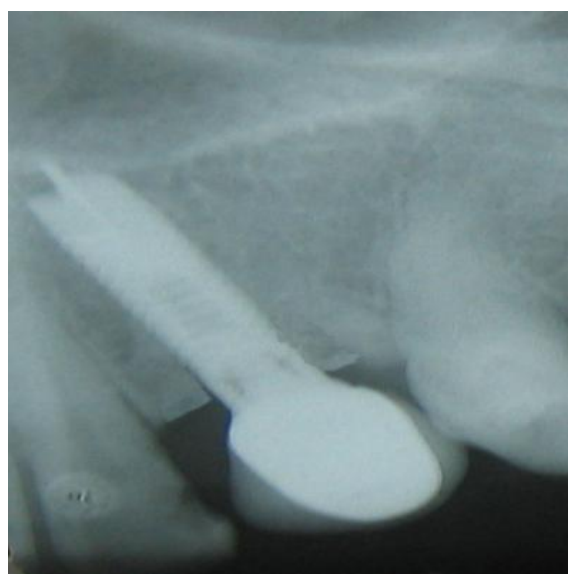

Fig 2: one year the defect shows favorable osseous changes.

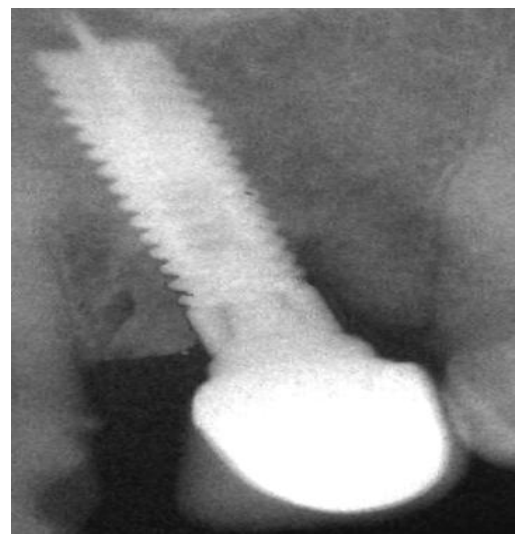

Fig 3: radiograph showing the bone level at six years follow up period

\section{Surgical Procedures}

Following the baseline examination thorough rinsing of the peri-implant pocket was performed with hydrogen perioxide and $2 \%$ aqueous solution of chlorohexidine gluconate; systemic metronidazole $(250 \mathrm{mg}$ once a day) was administered and maintained for 2 weeks. After 2 weeks of this hygienic phase the patients were prepared for the surgical procedure. Following local anaesthesia, full thickness flaps were elevated buccally and lingually. Granulation tissue was carefully removed by plastic curettes which was performed to remove all soft tissue from the defect. The implant surfaces were cleaned using $10 \%$ hydrogen perioxide followed by careful rinsing with saline. The bony defect in most instances was vertical and infrabony in nature. A composite bone graft formed of autogenous bone harvested from the chin and mixed with cancellous bovine porous bone mineral* "particle size 0.25 to 1.0 mm" was carefully packed using new plastic amalgam condensers to the level of the surrounding bone into the bony defect. The flap was then repositioned to completely cover and to carefully and tightly adapt around the neck of the implants using silk sutures. An antibiotic regimen was prescribed (3 times daily 250 $\mathrm{mg}$ of metronidazole and $375 \mathrm{mg}$ of amoxicillin) for ten days. The patient was instructed to rinse twice daily with $0.02 \%$ chlorohexidine. One week later, the sutures were removed. Regular check-up was performed monthly on the first year for professional cleaning and motivation of oral hygiene measures and yearly thereafter. The patients were recalled for reassessment of the clinical, radiographic and 
microbiological examination. The clinical parameters included probing depths, and probing bone level whereas grey level of bone around the implants were evaluated radiographically. All the clinical data was statistically analyzed using the student $t$ test while the microbiological data was analyzed by the chi square test.

\section{Results \\ Clinical Results}

Statistical analysis of change in the gingival bleeding showed a highly significant difference between the baseline and 1 year and with the baseline and 6 years. However, there was no significant difference between 1 year and 6 years table (1) fig. (4). The results of the present study revealed that all the cases showed favorable clinical and radiographic changes. The periimplant bony defects were apparent within the first 2 years of the functional phase. Sites with gingival bleeding decreased dramatically from $100 \%$ at the baseline to $10 \%$ after 1 year and 3\% at the six-year registration. Statistical analysis of change in the gingival bleeding showed a highly significant difference between the baseline, 1 year with the baseline and 6 years with the baseline. However, there was no significant difference between 1 year and 6 years. The mean probing depth over the experimental period was reduced from 6.94 \pm 1.16 to $3.00 \pm 1.36$ after one year, and it reached $1.91+1.21$ at the end of the study table (2) fig. (5). Moreover Statistical analysis of the bone level revealed highly significant differences between baseline and 6 years follow-up period $\mathrm{p}<0.01$ and between baseline and 1 year while there was no significant difference between 1 and 6 years. The baseline decreased from 7.02 \pm 1.71 to $4.32 \pm 1.67$ and $1.90 \pm 1.13$ at the end of the study period. Table (2) and fig.(6)

\section{Radiological Results}

Table (3) presents the comparison of bone density at baseline, 1 year, 6 years. the mean value of bone density at the crest, mid-implant and lateral apical area of interest AOI allover the follow-up period.
The mean bone density at the crestal area was $32.0 \pm 0.87$ at baseline, it was also $109.5 \pm 0.53$ and $108.38 \pm 1.41$ at 1 year. The statistical difference was highly significant between baseline and 1 year, and between baseline and 6 years follow-up period while there was insignificant differences between 1 and 6 years followup period. The mean value of bone density at the mid-implant AOI was $72.91 \pm 0.83$ at baseline reached $141.63 \pm 1.19$ and $140.5 \pm$ 1.07 at the end of the study. The bone density was at lateral apical AOI at baseline was $63.0 \pm 0.94$ and it was $144.0 \pm 0.47$ at 1 year. At 6 years follow-up period it was $143.0 \pm 0.94$ at the end of the follow-up period. The statistical analysis revealed significant difference between the baseline and the end of the study. Fig. (7) shows the comparison between the bone density at crest, mid, lateral apical AOI at baseline, 1 and 6 years.

\section{Microbiological results}

The composition of subgingival microbiota obtained from peri-implantitis sites and cultured for their identification is presented in table (4) and figure (8) Peptostreptococci was detected in $18.9 \%$ of sites at baseline and $12.1 \%$ after 6 years. Sixty five percent of Bacteroid fragilis was found at baseline and $21.7 \%$ was found at the end of the follow-up period. Porphyromonas gingivalis was detected in $75 \%$ at the baseline while it decreased to $13.4 \%$ at the end of the study. Similarly $80 \%$ of the sites showed the presence of Provetlla intermedia at baseline while it reached $22 \%$ at the end of the study period. $33.3 \%$ of the sites harboured enteric rods (Escherichia coli or Escherichia cloacae at the beginning of the study while at the end of the 6 year follow-up registration these species were recovered in $5.2 \%$ of sites. Fusobacterium nucleatum was detected at baseline in $50 \%$ of sites and it was not detected at the end of the study. Lactobacillus acidophilis was recovered in $33.3 \%$ of sites at baseline and dropped to10.3\% after 6 years. Conclusively, all patients harboured at least one of the marker organisms in a high percentage at baseline while the percentage of 
microorganisms declined at the end of the follow-up period. There was a statistical significant difference between the baseline and the end of the study period regarding all the microbiota harbouring the peri-implant sites

\section{Table (1): Gingival Index}

\begin{tabular}{|l|l|l|l|l|l|}
\hline Gingival Index & Baseline & 1 year & 6 years & P value & Significance \\
\hline Site & $100 \%$ & $10 \%$ & $3 \%$ & 0.000 & HS \\
\hline
\end{tabular}

P value: level of significance, Baseline: immediate postoperative, HS: highly significant

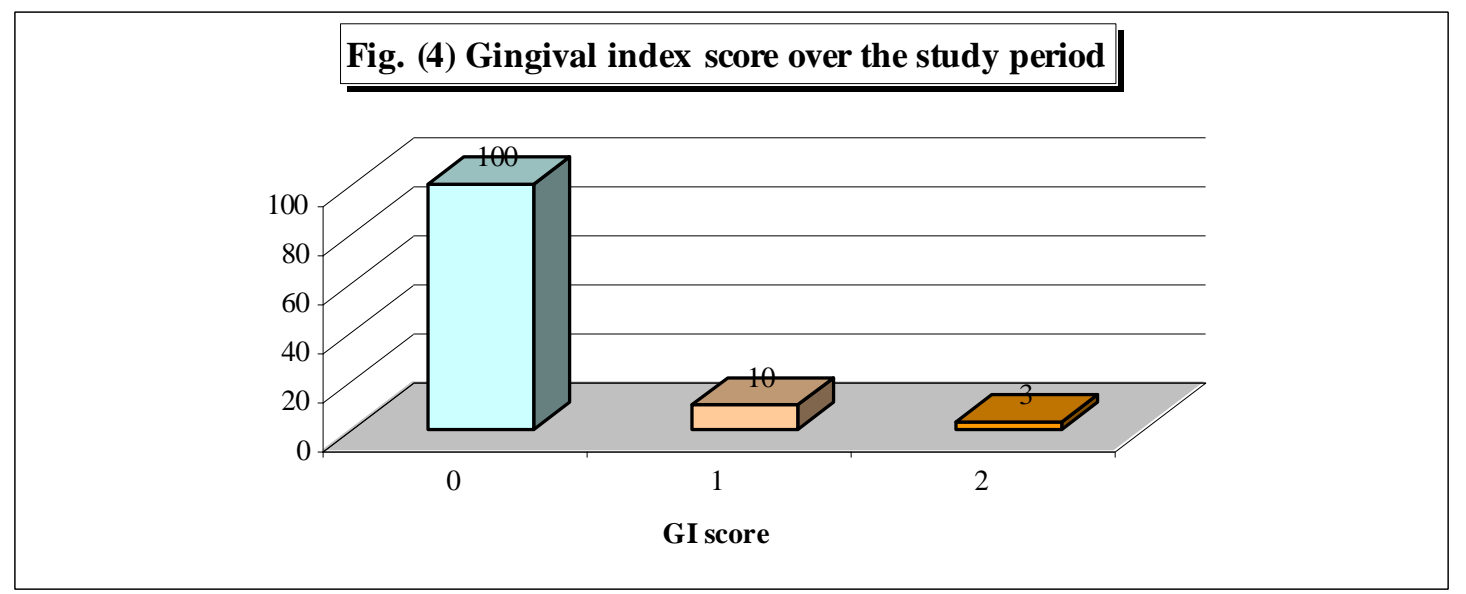

Table (2): Mean probing depth and bone level at the implant sites at different time intervals

\begin{tabular}{|l|l|l|}
\hline & Probing depth & Bone level \\
\hline At Baseline & $6.94+1.16$ & $7.02+1.71$ \\
\hline 1 year & $3+1.36$ & $4.32+1.67$ \\
\hline 6 years & $1.91+1.21$ & $1.90+1.13$ \\
\hline P value baseline \& 1 year & 0.000 & 0.002 \\
\hline Significance & HS & HS \\
\hline P value baseline \& 6 years & 0.000 & 0.000 \\
\hline Significance & HS & HS \\
\hline P value 1 year \& 6 years & 0.075 & 0.004 \\
\hline Significance & NS & HS \\
\hline Reduction in the Mean Pocket Depth & $5.03+0.05$ & \\
\hline Gain in Bone Level & & $5.12+0.5$ \\
\hline
\end{tabular}

$P$ value: level of significance, Baseline: immediate postoperative, NS; non- significant, HS: highly significant

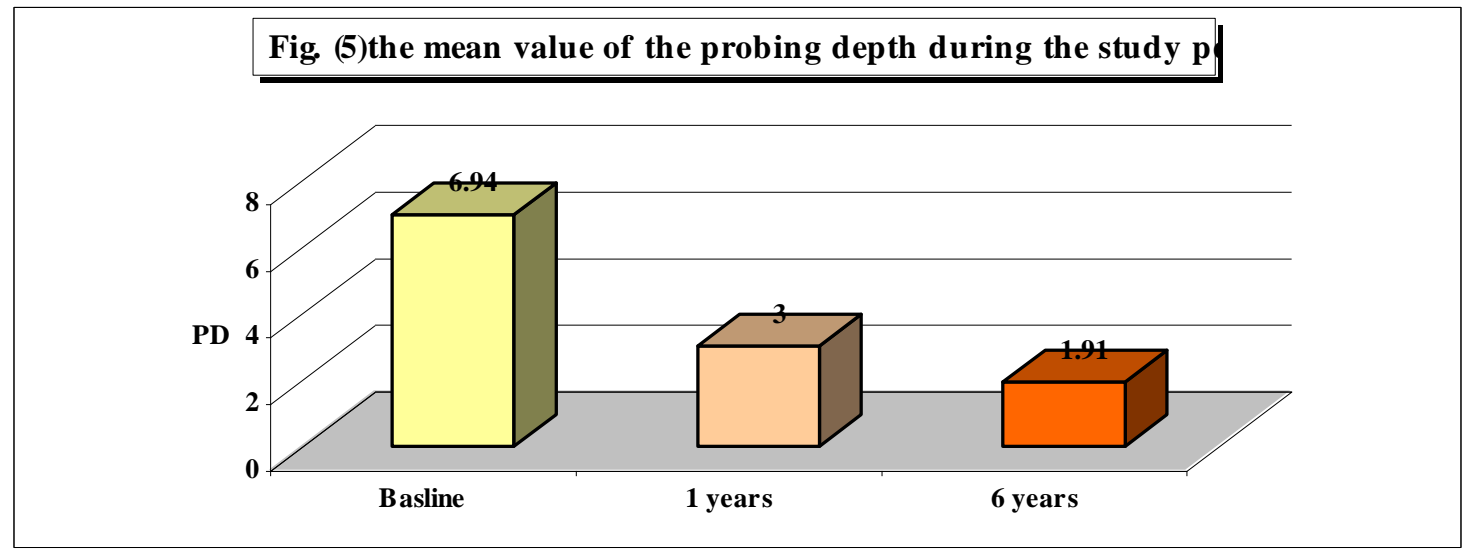




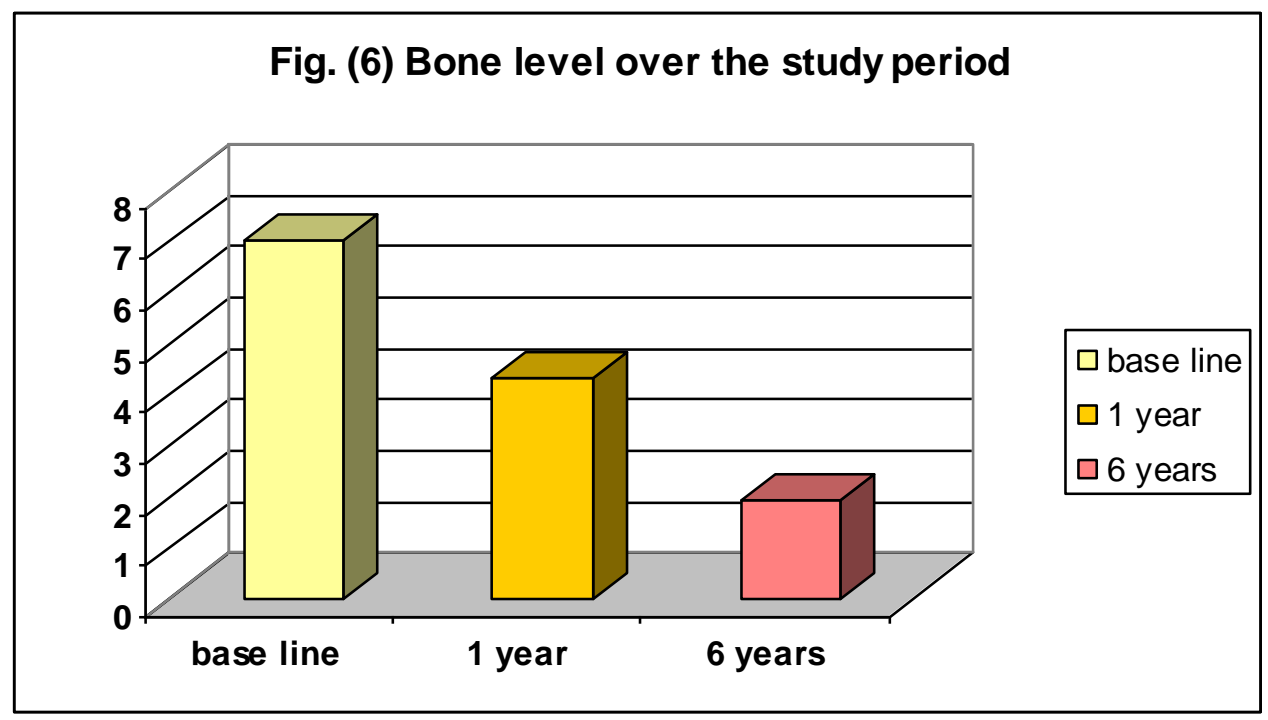

Table (3): Bone density around the implants at different sites and different time intervals

\begin{tabular}{|l|l|l|l|}
\hline Mean Bone Density & At Crest & Mid-implant & Lateral-apical \\
\hline At Baseline & $32.0+0.87$ & $72.91+0.83$ & $63.0+0.94$ \\
\hline 1 year & $109.5+0.53$ & $141.63+1.19$ & $144.0+0.47$ \\
\hline 6 year & $108.38+1.41$ & $140.5+1.07$ & $143.0+0.94$ \\
\hline P value (baseline \& 1 year) & 0.0000 & 0.000 & 0.000 \\
\hline Significance & HS & HS & HS \\
\hline P value (baseline \& 6 year) & 0.000 & 0.000 & 0.000 \\
\hline Significance & HS & HS & HS \\
\hline P value (1 year \& 6 year) & 0.92 & 0.959 & 0.979 \\
\hline Significance & NS & NS & NS \\
\hline
\end{tabular}

P value: level of significance, Baseline: immediate postoperative, NS; non- significant, HS: highly significant

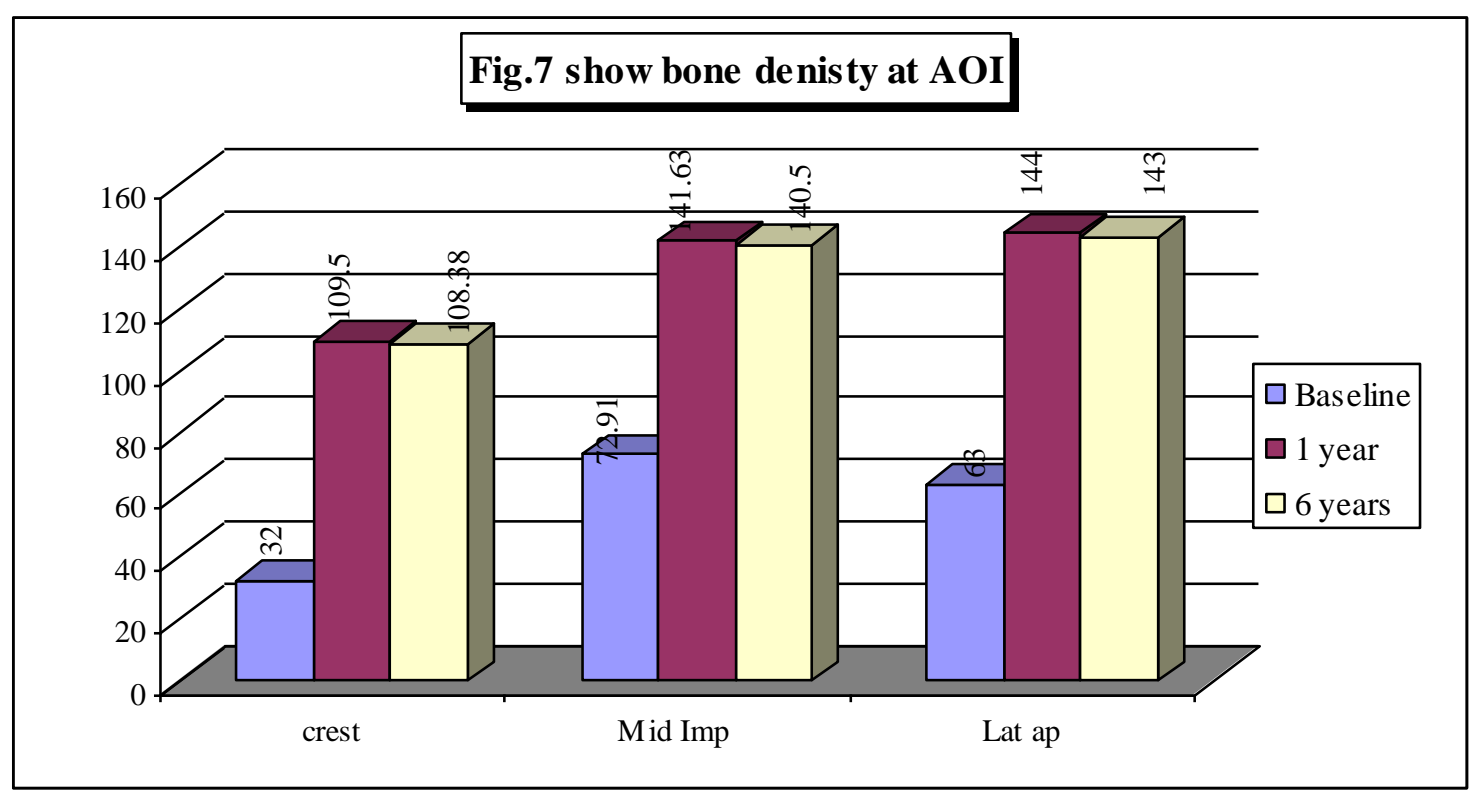


Table (4): The incidence of different microbes identified over the study period

\begin{tabular}{|l|l|l|l|l|l|}
\hline Microbiota & Baseline & 1 year & 6 years & P value & Significance \\
\hline Peptostreptococci & 18.9 & 15.3 & 12.1 & 0.01 & HS \\
\hline Bacteroid Fragilis & 65 & 33.3 & 21.7 & 0.00 & HS \\
\hline Enterorods & 33.3 & 22.2 & 5.2 & 0.23 & NS \\
\hline Porphyromonas Gingivalis & 75 & 20.7 & 13.4 & 0.00 & HS \\
\hline Provetlla Intermedia & 80 & 50 & 22 & 0.00 & HS \\
\hline Fusobacterium Nucleatum & 50 & 16.7 & 0 & 0.00 & HS \\
\hline Lactobacillus Acidophilis & 33.3 & 10.3 & 7.1 & 0.00 & HS \\
\hline
\end{tabular}

$\mathrm{P}$ value: level of significance, Baseline: immediate postoperative, NS: non- significant, HS: highly significant

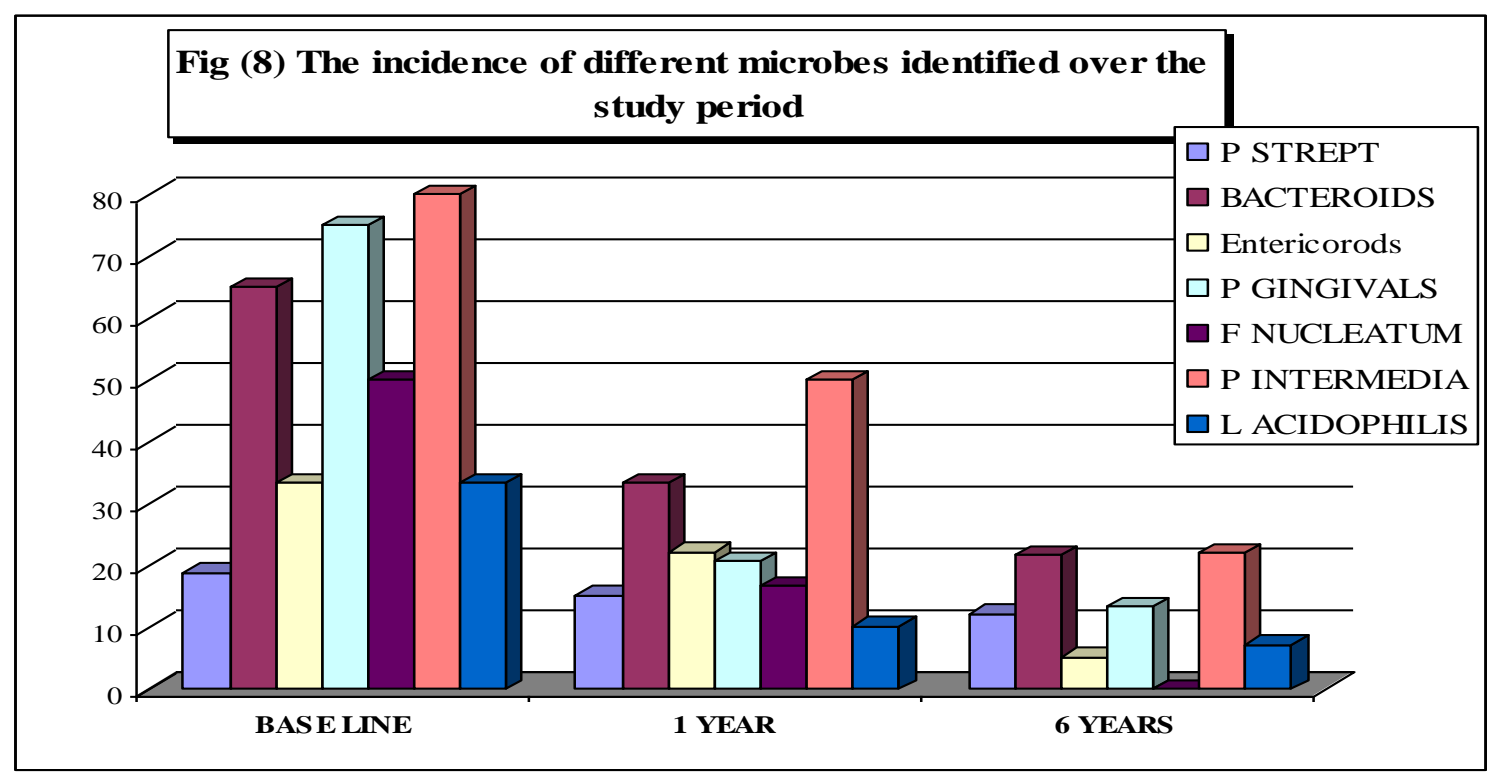

\section{Discussion}

The present study evaluated the longterm outcome of treatment of peri-implant destruction., which showed predictable results of maintaining implants treated for peri-implantitis using a treatment model consisting of surgical cleaning and guided bone regeneration for 6 years. Only the peri-implantitis cases with more than $5 \mathrm{~mm}$ probing depth that were in function for a minimum of 2 years were included.

Following elevation of a full thickness flap a transient burst of regional remodeling occurs. Starting with accelerated resorption activity followed by a slow process of bone regeneration $(1,35)$. In order to avoid this phenomenon, the flap in the present study was performed in a conservative manner to expose the area of the defect .Moreover, bone loss and remodeling after flap elevation without osseous surgery in periodontitis treatment, ranged from no resorption to $0.8 \mathrm{~mm}$.

At the time this study started, little was known about how to deal with infections around implants. Due to ethical reasons and the severity of the included cases, a control group was not included. Several animal studies and case reports investigated the possibility of regenerating new supporting bone around implants using guided bone regeneration (11) these studies produced contradictory results regarding GBR, ranging from no "reosseointegration" (13) to minimal reosseointergration (26) to clinically significant reosseointegration (15).

Infections around titanium implants is accompanied by plaque accumulation and 
are difficult to treat (34). From a clinical viewpoint, it may be insufficient to restrict treatment to scaling and polishing only. Therefore, the treatment approach in this study involved flap surgery in order to expose the bone and the fixture for more accessibility to mechanically clean the infected area by using $0.2 \%$ chlorohexidine, $10 \%$ hydrogen peroxide. The aim of this procedure was to disrupt the integrity of the biofilm, remove and to prevent recolonization of the vast majority of the microorganisms. This procedure was combined with the use of GBR. The GBR aimed at reconstruction of the lost bony support that was destroyed by the disease process. Several treatment procedures including the use of various bone grafts (27), bone substitutes and GTR (16), and growth factors were suggested for active regeneration of the tooth supporting apparatus. The ideal graft material is the one that is osteoinductive, absorbable, easy to handle, and available in large quantities (6). Autogenous bone meets the first three requisites, but obtaining the needed amount from the intraoral site is often problematic besides donor site morbidity. Allografts and alloplastic materials have been extensively used in regenerative surgery but their osteoinductive capabilities have been shown to be quite variable (31). More recently, a bovine derived xenograft has been introduced into periodontics. This material is available in an unlimited supply and proven safety (33). It is prepared by protein extraction of bovine bone but maintains the natural structure of bone (12).

When evaluating parameters such as inner surface area, porosity, crystalline size, and calcium-to-phosphorus ratio, bovine porous bone mineral BPBM most closely resembles human cancellous bone as compared to other allografts or synthetic hydroxyapatite materials (36). Several studies documented the ability of BPBM to enhance bone formation in sinus elevation procedures (37) around implants (4), and in critical-sized osseous defects (32). True histologic regeneration has been demonstrated in humans when using BPBM alone (22), but more complete and more predictable histologic regeneration was achieved when BPBM was used in combination with bioabsorbable membranes (7) and even more with autogenous bone alone (8). From the abovementioned reasons the composite graft used in the present study was BPBM and autogenous bone. Beheneke et al (3), reported a $3.5 \mathrm{~mm}$ reduction in probing depth and a $2.2 \mathrm{~mm}$ gain in clinical attachment level, the study utilized autogenous bone graft as an augmentation material owing to the possibility of cellular viability and consequent rapid vascularization. Ragy et al (29) reported $2.28 \mathrm{~mm}$ reduction in probing depth \& $2.44 \mathrm{~mm}$ gain in bone level in the treatment of peri-implantitis using alloplast bone graft. Our results showed a reduction in probing depth of $5.03+0.05 \mathrm{~mm}$ and a gain in bone level of $5.12+0.5 \mathrm{~mm}$ with the use of composite bone graft which proved to be statistically significant and in accordance with previous studies $(3,29)$. However, Grunder et al (13) showed a lower potential for bone regeneration, which could be explained partly by the anatomic variations of the bony defects, which were horizontal bony defects as opposed to the intrabony defects in the present study. On the other hand the superior results obtained in this study may be attributed to the combination between autogenous bone \& BPBM graft materials. The results of the present study revealed that it was not difficult to restore a healthy situation in conjunction with implants over a 6 year period. The gingival inflammation was resolved and new bone formation occurred.

The changes in the bone density around the implants were studied radiographically which revealed that all the treated implants were well integrated with no further bone loss or periapical radiolucencs. Moreover there was a significant increase in the density of bone at the three areas of interist around the treated implants. This increase in bone density was significantly higher at one and six years follow up period. The result of the change in bone density was in accordance with Ragy etal, 2001 who reported favorable osseous changes in response to bone graft in the treatment of periimplatitis. 
Regarding the microbiological findings in the present study there was a significant reduction and total elimination of other pathogenic bacteria which were detected from the beginning of the study. The results were in accordance with the results of Leonhardt et al (19) who reported a total elimination of actinomycetem comitance and the enteric rods in long-term periimplantitis treatment. The obvious decrease in the percentage of microorganisms which harboured the sites at the end of the study highlighted the need for long-term plaque control to maintain the health of the implant soft and hard tissue interface.

\section{Conclusions}

The results of the present study suggest that the combination between autogenous and BPBM bone grafts appears to be an efficacious treatment approach for restoring bone around dental implants following progressive bone loss caused by peri-implantitis. The present method resulted in successful clinical and radiographic bone fill and resolved the periimplantitis lesion over an observation period of 6 years.

\section{References:}

1. Aesclimann, CR; Robinson, PJ and Kaminski, EJ: A short-term evaluation of periodontal surgery. J Periodont Res. 14: 182,1979

2. Becker, $\mathbf{W}$ and Becker, BE: Guided tissue for implant placed into extraction socket and for implant dehiscence. Surgical techniques and case report. Int $\mathbf{J}$ Periodontal Res. 10: 337,1990

3. Behneke, A; Behneke, $\mathbf{N}$ and Hoedt, B: Treatment of peri-implantitis defects with autogenous bone grafts: Six-month to 3year results of a prospective study in 17 patients. Int J Oral Maxillofac Implants 15: 125,2000

4. Berglundh, $\mathbf{T}$ and Lindhe, $\mathbf{J}$ : Healing around implants placed in bone defects treated with Bio-Oss. Clin Oral Impl Res 8: 117, 1997

5. Buchmann, R; Khoury, F; Pingel, D: Muller, RF and Lange, DE: Intraimplant microbiota of oral implants. J Dent Res 79: 168,2000
6. Camargo, PM; Lekovic, V; Weinlader, $M$; Nedic, M; Aleksic, $Z$ and Kenney, EB: A comparison between enamel matrix proteins used alone or in combination with bovine porous bone mineral in the treatment of intrabony periodontal defects in humans. J Periodontol 71: 1110, 2000

7. Camelo, M; Nevins, ML and Schenk, RK: Clinical, radiographic and histologic evaluation of human periodontal defects treated with Bio-Oss and Bio-Gide. Int $\mathbf{J}$ Periodont Rest Dent 18: 321,1998

8. Camelo, M; Nevins, ML; Lynch, SE; Schenk, RK; Simion, $M$ and Nevins, M: Periodontal regeneration with an autogenous bone Bio-Oss composite graft and a Bio-Gide membrane. Int J Periodont Rest Dent 21:109,2001

9. Esposito, M; Hirsch, JM; Lekholm, U and Thomsen, P: Biological factors contributing to failures of osseointegrated oral implants I. Success criteria and epidemiology. Eur. J Oral Sci 106: 527,1998

10. Esposito, M; Hirsch, JM; Lekholm, U and Thomsen, P: Biological factors contributing to failures of osseointegrated oral implants. II. Etiopathogenesis. Eur. J Oral Sci. 106: 721, 1998

11. Esposito, M; Hirsch, JM; Lekholm, U and Thomsen, P: Differential diagnosis and treatment strategies for biologic complications and failing oral implant review of literature. Int J Oral Maxillofac Implants 14: 473,1999

12. Gross, J: Bone grafting materials for dental applications: A practical guide. Compend. Cont. Educ Dent. 18: 1013, 1997

13. Grunder, U; Hurzeler, MB; Schupbch, $\mathbf{P}$ and Strub, JR: Treatment of ligatureinduced peri-implantitis using guided tissue regeneration: A clinical and histologic study in the beagle dog. Int $\mathrm{J}$ Oral Maxillofac Implants 8: 282,1993

14. Hammerle, CHF; Fourmousis, I; Winkler, JR; Weigel, $C$; Bragger, $U$ and Lang, NP: Successful bone fill in late periimplant defects using guided tissue regeneration. A short communication. J Periodontol 66: 303,1995

15. Hurzeler, MB; Quinones, CR; Schupback, P; Morrison, EC and Cafesse, RG: Treatment of peri-implantitis using guided bone regeneration and bone grafts, alone or in combination in beagle dogs. Part 2: Histologic findings. Int J Oral Maxillofac Implants. 12: 168,1997 
16. Kenney, EB; Lekovic, V; Ferreira, JC; Han, T; Dimitrijevic, $B$ and Carranza, FA: Bone formation within porous hydroxyapatite implants in human periodontal defects. J Periodontol 57: 76,1986

17. Kerr, DA and Millard, HD: Oral diagnosis. St Louis, CV. Mosby Company, 1965

18. Khoury, F and Buchmann, R: Surgical therapy of peri-implant disease: A 3-year follow-up study of cases treated with 3 different techniques of bone regeneration. $\mathrm{J}$ Periodontol 72: 1498, 2001

19. Leonhardt, A; Dahlin, G and Renvert, S: Five-year clinical, microbiological and radiological outcome following treatment of peri-implantitis in man. J Periodontol 74: 1415,2003

20. Leonhardt, A; Renvert, S and Dahlin, G: Microbial findings of failing implants. Clin Oral Implants Res 10: 339,1999

21. Meffert, RM: How to treat failing implants. Implant Dent 1: 25, 1992

22. Mellonig, T: Human histologic evaluation of a bovine-derived xenograft in the treatment of periodontal osseous defects. Int J Periodont Rest Dent 20: 18, 2000

23. Misch, E. Carl: Contemporary implant dentistry. Mosby. ST. Louis, 1993

24. Mombelli, A and Lang, NP: The diagnosis and treatment of peri-implantitis. Periodontol 2000. 21: 63, 1998

25. Mombelli, A: Prevention and therapy of periimplant infections. In Lang, NP; Karring, $\mathrm{T}$ and Lindhe, J.: Proceedings of the $3^{\text {rd }}$ European workshop on periodontology: Implant dentistry. Berlin: Quintessence publishing, 1999

26. Presson, LG; Ericsson, I; Berlundh, T and Lindhe, J: Guided bone regeneration in the treatment of peri-implantits. Clin Oral Implants Res. 8: 66, 1997

27. Quintero, G; Mellonig, J; Gambill, V and Pelleu, GJr: A 6 month clinical evaluation of decalcified freeze dried bone allografts in periodontal osseous defects. J periodontal 53: 726,1982
28. Quirynen, M and De Sock, ML; Van Steenberghe, D: Infectious risk for oral implants: A review of the literature. Clin Oral Implant Res. 13: 1, 2002

29. Ragy, N; Ezz El Arab and Gawish, A: Clinical and radiographic evaluation of alloplast bone graft in management of periimplantitis. Egyptian Dent J 47:241, 2001

30. Richter, EJ; Jansen, V; Spikermann, H and Jovanovic, SA: Long-term results with IMZ and TPS implants in the interforamine area in the edentulous area. Dtsch Zahnartztl Z 74: 449,1999

31. Schwartz, Z; Mellonig, JT and Carnes, DL: Ability of commercial demineralized freeze-dried bone allograft to induce new bone formation. J Periodontol 67:918,1996

32. Schmitt, JM; Buck, DC; Joh SP; Lynch, SE and Hollinger, JO: Comparison of porous bovine mineral and biologically active glass in critical-sized defects. J Periodontol 68: 1043, 1997

33. Sehlickewei, $W$ and Paul, C: Experimental investigations of bone replacement using bovine apatite. Hefte zur Unfall Heikunde 216: 59, 1991

34. Sennerby, L; Lekholm, U; Ericsson, I: Soft tissue response to clinically retrieved titanium cover screws reimplanted in the rat abdominal wall. Int $\mathbf{J}$ Oral Maxillofac Implants 4:233,1989

35. Smith, D; Ammons, $W$ and Van Belle, G: A longitudinal study of periodontal status comparing osseous recontouring with flap curettage. I. Results after 6 months. J Periodontol 51: 367,1980

36. Valdre, G; Mongiorgi, R; Ferrieri, P; Cervo, G; Cattaneo, V and Eartaro, G: Scanning electron microscopy and microanalysis applied to the study of biomaterials for dental use. Minerva Stomatologica 44:55,1995

37. Valentini, $\mathbf{P}$ and Abensur, D: Maxillary sinus floor elevation for implant placement with demineralized freeze-dried bone and bovine bone (Bio-Oss): A clinical study of 20 patients. Int J Periodont Rest Dent 17: 233, 1997 


\title{
تقيم نتائج ستة أعوام من الدراسة الإكلينيكية و الميكروبيولوجية

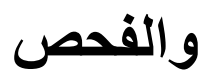 بالأشعة العلاجية الالتهاب حول الغرسات
}

\author{
عبير سعد جاويش ، سوزان عبد الحكيم حسان \\ كلية طب الأسنان بنات - جامعة الأزهر هري
}

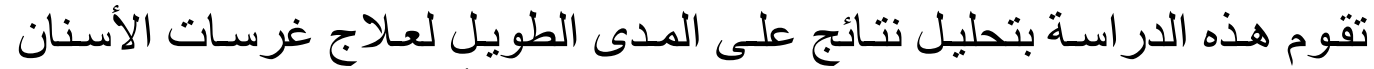

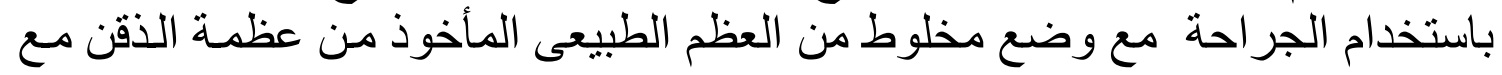
جزئيات مفر غة من العظم البقرى . ضم هذا البحث ست أفر اد يعانون من تأكل في العظم حول غرسات التهات التايتنوم .

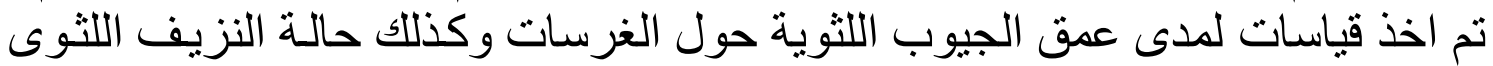

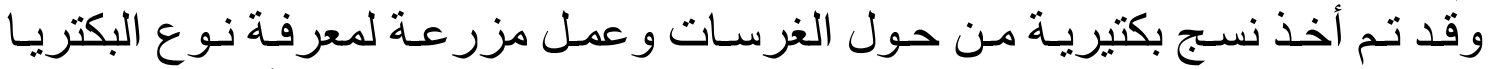

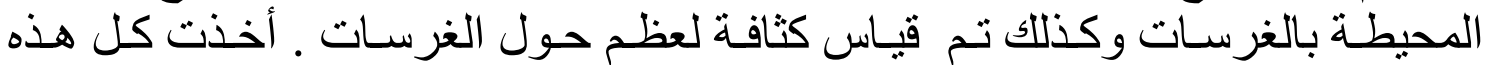

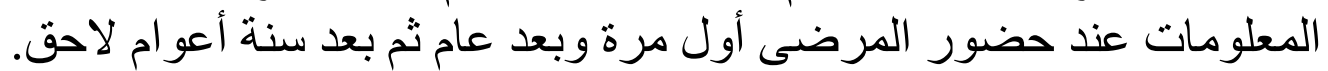

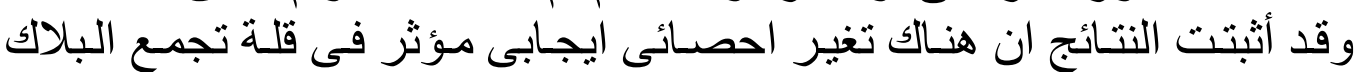

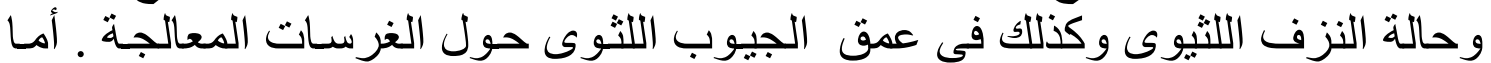

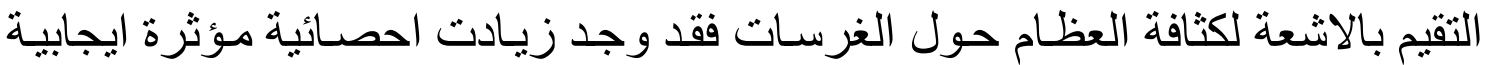

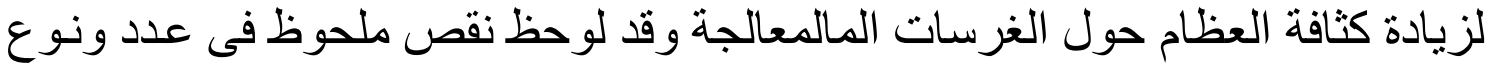
البكتريا الممرضة عند نهاية البحث .

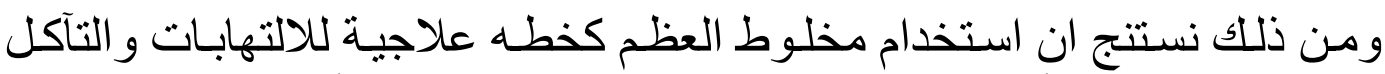

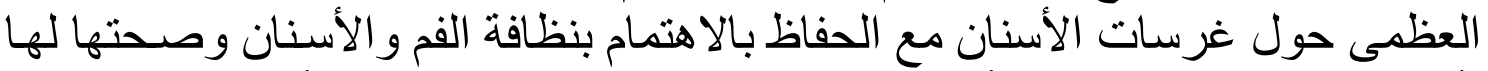

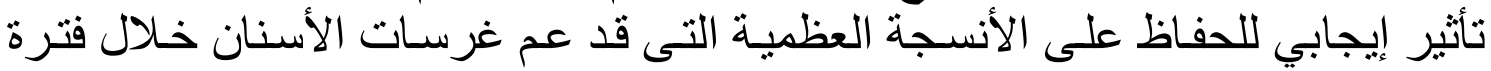

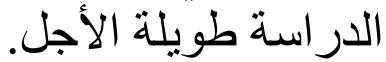

